\title{
Early Experience of High-dose Intravenous Mycobacterium w in Critically Ill Patients of COVID-19
}

\author{
Parth Sudhendu Patel ${ }^{1} \odot$, Sudhendu Patel ${ }^{2}$, Vidhi Shah $^{3}$, Varsha Aswani $^{4} \odot$, Mahendra Narwaria $^{5} \odot$
}

\begin{abstract}
Background: Immune dysregulation is one of the main reasons for mortality and morbidity in coronavirus disease 2019 (COVID-19). Mycobacterium w $(\mathrm{Mw})$ is recently approved for gram-negative sepsis. Moreover, it is also found effective in COVID-19 patients in previous studies. The traditional route of administration for $\mathrm{Mw}$ is intradermal, which has a limitation of administering $0.1 \mathrm{~mL}$ per injection and local injection site reaction. Intravenous (IV) administration of Mw has not been explored in COVID-19. We report the retrospective analysis of six critically ill COVID-19 patients who received Mw (IV).

Patients and methods: At baseline, all patients in this case series required $\mathrm{O}_{2}$ supplementation, and their inflammatory biomarkers were elevated. All patients received $0.6 \mathrm{~mL} \mathrm{Mw}$ (high-dose) in normal saline along with the standard-of-care treatment.

Results: After $\mathrm{Mw}$ administration, gradual improvement in $\mathrm{O}_{2}$ requirement was observed and patients were discharged from the hospital with no mortality. A reduction in mean C-reactive protein (CRP) (51.48-18.52 mg/dL), interleukin-6 (IL-6) $(260.22-14.47$ pg/mL), and FiO 2 (81.67-43.33) was also observed. No side effects were observed with the use of Mw by IV route.

Conclusion: Use of $0.6 \mathrm{~mL} \mathrm{Mw}$ by IV route in this case series was associated with decreased $\mathrm{O}_{2}$ supplementation without any side effects in critically ill patients of COVID-19.

Keywords: COVID-19, Immune dysregulation, Immunomodulator, Mycobacterium w.

Indian Journal of Critical Care Medicine (2021): 10.5005/jp-journals-10071-23963
\end{abstract}

\section{INTRODUCTION}

Coronavirus disease 2019 (COVID-19) pneumonia is associated with significant mortality and morbidity particularly in critically ill patients requiring $\mathrm{O}_{2}$ supplementation. Morbidity and mortality associated with sepsis (bacterial as well as viral, including COVID-19) is due to infection-induced immune dysregulation (impaired immune homeostasis) rather than infection per se. ${ }^{2,3}$ Establishment of immune homeostasis is one of the suggested approaches to reduce the morbidity and mortality associated with COVID-19, especially in critically ill patients. ${ }^{4}$

Mycobacterium $w(M w)$ is an immunomodulator approved for the treatment of gram-negative sepsis, ${ }^{5}$ which helps in reestablishing immune homeostasis. It also reduces the mortality associated with gram-negative sepsis. ${ }^{6}$ The efficacy of $\mathrm{Mw}$ in gram-negative sepsis is proportionate to the administered dose of $\mathrm{Mw}$. The recommended dose of $\mathrm{Mw}$ for gram-negative sepsis is $0.3 \mathrm{~mL}$ daily for 3 days. And $0.3 \mathrm{~mL}$ of Mw needs to be administered as three intradermal injections of $0.1 \mathrm{~mL}$ each, as intradermal route has a limitation of dose per site of $0.1 \mathrm{~mL}$. Like Bacille Calmette-Guerin, intradermal $\mathrm{Mw}$ is also associated with local site reaction. Immune dysregulation seen in gram-negative sepsis and COVID-19 is identical. ${ }^{7}$ The use of intradermal Mw in the management of COVID-19 is also associated with improved outcomes. ${ }^{8-10}$

Intravenous (IV) administration of mycobacterial immunomodulator is associated with better immune response in lung parenchyma compared to intradermal administration. ${ }^{11}$ Administration of Mw by the IV route is also described to be safe and effective. ${ }^{12}$ IV route of administration of Mw offers (i) ease of administration as it can be given through the secured ongoing IV line, (ii) ability to give desired additional amount as a single injection, and (iii) delivery of the drug to the lungs. Intradermal
${ }^{1}$ Department of Critical Care, Bombay Hospital, Institute of Medical Sciences, Ahmedabad, Gujarat, India

${ }^{2-3}$ Department of Medicine, Sterling Hospital, Ahmedabad, Gujarat, India

${ }^{4}$ Department of Surgery, VS Hospital, Ahmedabad, Gujarat, India

${ }^{5}$ Department of Surgery, Asian Bariatrics Hospital, Ahmedabad, Gujarat, India

Corresponding Author: Parth Sudhendu Patel, Department of Critical Care, Bombay Hospital, Institute of Medical Sciences, Ahmedabad, Gujarat, India, Phone: +91-079-26854876, e-mail: parthtonypatel@ gmail.com

How to cite this article: Patel PS, Patel S, Shah V, Aswani V, Narwaria M. Early Experience of High-dose Intravenous Mycobacterium w in Critically III Patients of COVID-19. Indian J Crit Care Med 2021;25(9):1066-1068.

Source of support: Nil

Conflict of interest: None

administration needs additional training/skill that is not required for IV administration in the intensive care unit setting. The highest dose administered so far by intradermal route is $0.3 \mathrm{~mL} /$ day compared to a dose as high as $5.0 \mathrm{~mL} /$ day by IV route. ${ }^{12,13}$ IV administration of $\mathrm{Mw}$ in the management of gram-negative sepsis or COVID-19 is not known. In this case series, we present retrospective analysis of the administration of $0.6 \mathrm{~mL} /$ day of $\mathrm{Mw}$ by IV route in the critically ill patients of COVID-19.

\section{Case Description}

This case series describes the clinical course of six critically ill patients (three male and three female) treated with IV Mw. All 
Table 1: Baseline characteristics

\begin{tabular}{|c|c|c|c|c|c|c|}
\hline Patients & 1 & 2 & 3 & 4 & 5 & 6 \\
\hline Age/sex & $85 / F$ & $49 / F$ & $54 / \mathrm{M}$ & $24 / \mathrm{M}$ & $53 / F$ & $73 / \mathrm{M}$ \\
\hline Ct value & 26 & 32 & 24 & 15 & 25 & 20 \\
\hline Comorbidities & $\begin{array}{l}\text { Diabetes mellitus, } \\
\text { hypertension }\end{array}$ & Morbid obesity & $\begin{array}{l}\text { Splenic vein } \\
\text { thrombosis }\end{array}$ & - & $\begin{array}{l}\text { Diabetes } \\
\text { mellitus }\end{array}$ & $\mathrm{CABC}$ \\
\hline $\mathrm{O}_{2}$ requirement & NIV & NIV & NIV & $\mathrm{NC}$ & NRBM & NIV \\
\hline Symptoms & $\begin{array}{l}\text { Fever, breathlessness, } \\
\text { dyspnea }\end{array}$ & & & & & \\
\hline
\end{tabular}

Ct, cycle threshold; NIV, noninvasive ventilation; NC, nasal cannula; NRBM, non-rebreathing mask; CABG, coronary artery bypass grafting

Table 2: Changes following IV Mw for 3 days along with standard treatment

\begin{tabular}{|c|c|c|c|c|c|c|c|c|c|c|c|c|}
\hline \multirow[b]{2}{*}{ Patients } & \multicolumn{2}{|c|}{1} & \multicolumn{2}{|c|}{2} & \multicolumn{2}{|c|}{3} & \multicolumn{2}{|c|}{4} & \multicolumn{2}{|c|}{5} & \multicolumn{2}{|c|}{6} \\
\hline & Pre & Post & Pre & Post & Pre & Post & Pre & Post & Pre & Post & Pre & Post \\
\hline $\mathrm{O}_{2}(\mathrm{Fi})$ & 95 & 75 & 100 & 70 & 70 & 55 & 75 & RA & 80 & RA & 70 & 60 \\
\hline $\begin{array}{l}\text { Mode of } \mathrm{O}_{2} \\
\text { supplement }\end{array}$ & NIV & NIV & NIV & HFNC & NIV & NRBM & NC & RA & NRBM & RA & NIV & NRBM \\
\hline CRP & 28 & 51 & 73 & 7 & 78 & 9 & 45.78 & 7.8 & 14.1 & 13.3 & 70 & 23 \\
\hline IL6 & 941 & 19 & 10.8 & NA & 16.2 & 5.6 & 11.7 & NA & 36 & 23 & 47.7 & 10.3 \\
\hline
\end{tabular}

NIV, noninvasive ventilation; HFNC, high-flow nasal cannula; NC, nasal cannula; NRBM, non-rebreathing mask; RA, room air

the patients had COVID-19, confirmed by reverse transcriptasepolymerase chain reaction (RT-PCR) test, and were receiving supplemental $\mathrm{O}_{2}$. All but one patient had associated comorbidities like diabetes mellitus, hypertension, obesity, history of CABG, and splenic vein thrombosis (Table 1). Baseline mean C-reactive protein (CRP) was $51.48 \mathrm{mg} / \mathrm{dL}$. Supplemental $\mathrm{O}_{2}$ was provided by noninvasive mechanical ventilation to four and via non-rebreathing mask or nasal cannula to the others. All patients received inj remdesivir, methylprednisolone, and antibiotics (doxycycline or azithromycin) as per institutional protocol along with Mw (Sepsivac, Cadila Pharmaceuticals, Ahmedabad, India). Mw was administered as $0.6 \mathrm{~mL}$ of Mw per day diluted with $100 \mathrm{~mL}$ of normal saline and was administered for three consecutive days through IV line secured for the administration of medications within 1 to 2 hours of administration of glucocorticoids.

Mw was well-tolerated in all patients, and no adverse event was seen. All the patients improved and were discharged from the hospital. Following the administration of Mw for 3 days, there was an improvement in $\mathrm{FiO}_{2}$ (Fig. 1) in all and a reduction in $\mathrm{O}_{2}$ requirement in all but one patient. Reduction in supplemental $\mathrm{O}_{2}$ requirement device (graded as per the increasing requirement of $\mathrm{O}_{2}$ supplementation device; patient on room air being grade 0 and requirement of mechanical ventilation being grade 5) was associated with a decrease in CRP (Table 2; Fig. 2). The patient with no change in supplemental $\mathrm{O}_{2}$ requirement had an increase in CRP. Interleukin-6 (IL-6) reduction was seen in all patients. The mean change in CRP, IL-6, and $\mathrm{FiO}_{2}$ was from 51.48 to $18.52 \mathrm{mg} / \mathrm{dL}$ ( $p=0.079), 260.22$ to $14.47 \mathrm{pg} / \mathrm{mL}(p=0.355), 81.67$ to 43.33 $(p=0.029)$, respectively, on day 4 after the administration of $\mathrm{Mw}$ for three consecutive days.

\section{Discussion}

Spike-S protein-induced upregulation of endosomal TLRs-is responsible for immune dysregulation seen in COVID-19. Mw is known to induce TLR2 (Th1 response) while downregulating upregulated endosomal TLRs to reestablish immune homeostasis, thereby improving outcomes in the management of Gramnegative sepsis. ${ }^{6,9,14} \mathrm{Mw}$ is also known to improve CD4 count in immunocompromised individuals with lower CD4 count. ${ }^{15}$ Conventional route of administration of $\mathrm{Mw}$ is the intradermal route. In this study, the IV route of administration allowed ease of administration as well as higher dose $(0.6 \mathrm{~mL} /$ day instead of $0.3 \mathrm{~mL} /$ day). This was found to be safe. It was also associated with improvement in lung function as indicated by a change in $\mathrm{FiO}_{2}$ and mode of $\mathrm{O}_{2}$ supplementation.

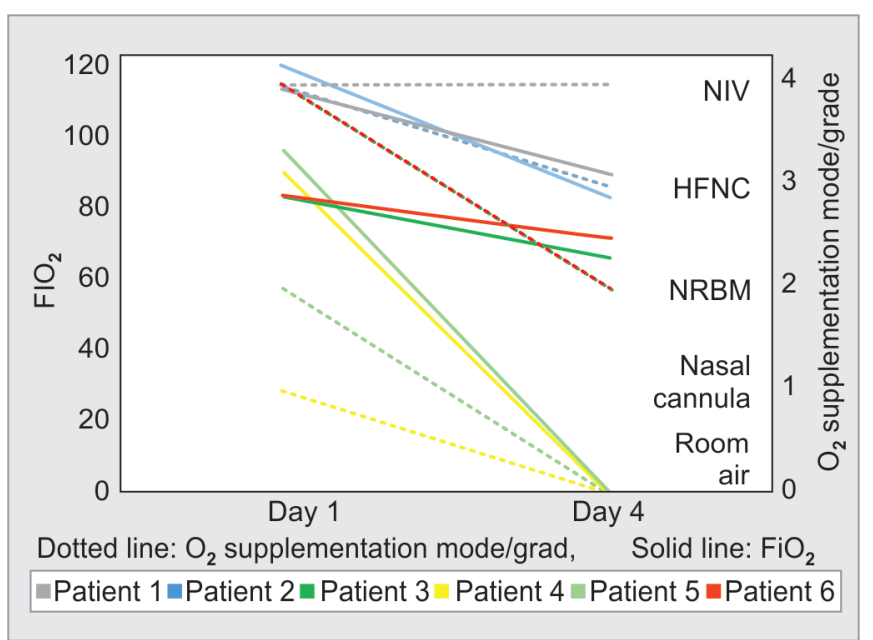

Fig. 1: Changes in $\mathrm{O}_{2}$ requirement status after the administration of $\mathrm{Mw} 0.6 \mathrm{~mL}$ for three consecutive days. Grade 0-room air (RA); grade 1-nasal cannula (NC); grade 2-non-rebreathing mask ventilation (NRBM); grade 3-high-flow nasal cannula (HFNC); grade 4-noninvasive ventilation (NIV); grade 5-mechanical ventilation 


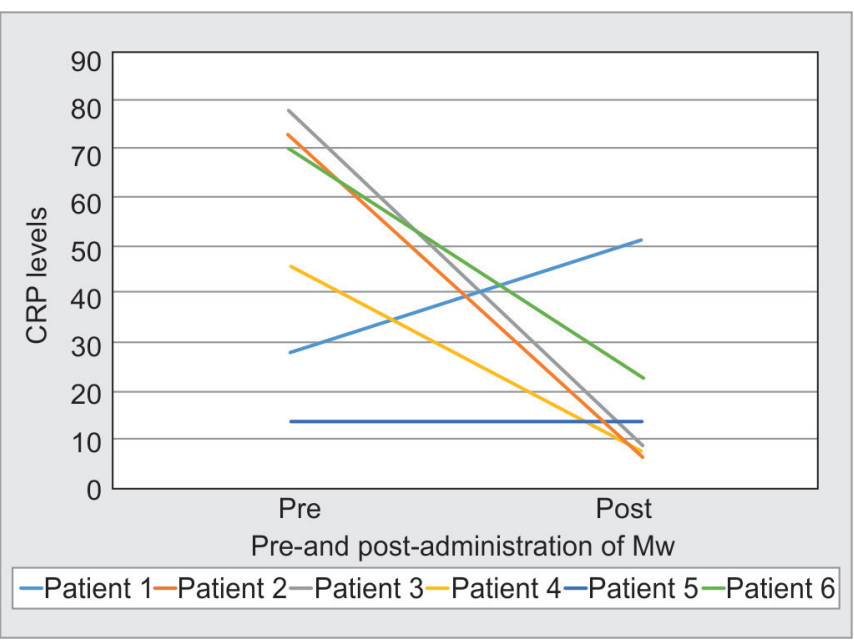

Fig. 2: Change in CRP after the administration of $\mathrm{Mw}$

The observed improvement in $\mathrm{O}_{2}$ requirement in patients could be attributed to the improvement in the pulmonary pathology. This was also evident by a decrease in the mode of $\mathrm{O}_{2}$ supplementation.

Safety of addition of $0.6 \mathrm{~mL}$ of Mw to standard of treatment observed in this case series is in accordance with previous reports. ${ }^{12,13}$ It also paves way for evaluating Mw via the IV route in a larger study.

\section{OrCID}

Parth Sudhendu Patel (10 https://orcid.org/0000-0002-0061-5721

Varsha Aswani @ https://orcid.org/0000-0002-8495-0227

Mahendra Narwaria — https://orcid.org/0000-0002-0611-1567

\section{References}

1. Al-Rifai RH, Acuna J, Al Hossany Fl, Aden B, Al Memari SA, Al Mazrouei SK, et al. Epidemiological characterization of symptomatic and asymptomatic COVID-19 cases and positivity in subsequent RT-PCR tests in the United Arab Emirates. medRxiv 2020.09.23.20200030. DOI: 10.1101/2020.09.23.20200030.
2. Ren C, Yao RQ, Ren D, Li Y, Feng YW, Yao YM. Comparison of clinical laboratory tests between bacterial sepsis and SARS-CoV2-associated viral sepsis. Mil Med Res 2020;7(1):36. DOI: 10.1186/ s40779-020-00267-3.

3. Yazdanpanah $F$, Hamblin MR, Rezaei N. The immune system and COVID-19: friend or foe? Life Sci 2020;256:117900. DOI: 10.1016/j. Ifs.2020.117900.

4. Yang L, Liu S, Liu J, Zhang Z, Wan X, Huang B, et al. COVID-19: immunopathogenesis and Immunotherapeutics. Signal Transduct Target Ther 2020;5(1):128. DOI: 10.1038/s41392-020-00243-2.

5. Sepsivac [package insert]. Ahmedabad, India: Cadila Pharmaceuticals Limited; 2019.

6. Sehgal IS, Basumatary NM, Dhooria S, Choudhuri R, Shah C, Agarwal $\mathrm{R}$, et al. A randomized trial of Mycobacterium $w$ in severe presumed gram-negative sepsis. Chest 2021;S0012-3692(21)00680-2. DOI: 10.1016/j.chest.2021.03.062.

7. López-Collazo E, Avendaño-Ortiz J, Martín-Quirós A, Aguirre LA. Immune response and COVID-19: a mirror image of sepsis. Int J Biol Sci 2020;16(14):2479-2489. DOI: 10.7150/ijbs.48400.

8. Sehgal IS, Bhalla A, Puri GD, Yaddanapudi LN, Singh M, Malhotra P,et al. Safety of an immunomodulator Mycobacterium w in COVID-19. Lung India 2020;37(3):279-281. DOI: 10.4103/lungindia.lungindia_242_20.

9. Sehgal IS, Guleria R, Singh S, Siddiqui MS, Agarwal R. A randomised trial of Mycobacterium w in critically ill patients with COVID-19: ARMY-1. ERJ Open Res 2021;7(2):00059-2021. DOI: 10.1183/23120541.00059-2021.

10. Ingale A, Ingale F, Kunwar B, Ahmed S, Salvi K, Chavan V, et al. Role of Mycobacterium w for the treatment of COVID-19: an observational study. J Assoc Physicians India 2021;69(1):19-22. https://www.japi.org/ x2747444/role-of-mycobacterium-w-for-the-treatment-of-covid-19an-observational-study

11. Darrah PA, Zeppa JJ, Maiello P, Hackney JA, Wadsworth II MH, Hughes TK, et al. Prevention of tuberculosis in macaques after intravenous BCG immunization. Nature 2020;577:95-102. DOI: 10.1038/s41586019-1817-8.

12. Pant MC, Verma VP. Intravenous Cadi05: phase I single dose study. J Clin Oncol 2008;26(15_suppl):14019-14019. DOI: 10.1200/ jco.2008.26.15_suppl.14019.

13. Sudhalkar A, Khamar A, Khamar B. Outcomes of toll-like receptors' antagonism in steroid-resistant optic neuritis; a pilot study. Graefes Arch Clin Exp Ophthalmol 2012;250(6):871-877. DOI: 10.1007/s00417011-1896-1.

14. Desai NM, Khamar BM. Immunotherapy for tuberculous pericarditis. N Engl J Med 2014;371(26):2533-2534. DOI: 10.1056/NEJMc1413185.

15. Kharkar R. Immune recovery in HIV with Mycobacterium w. J Indian Med Assoc 2002;100(9):578-579. PMID: 12455393. 